\title{
BIJDRAGE TOT DE KENNIS DER VEREERING VAN WISNU OP JAVA \\ DOOR
}

DR. H. H. JUYNBOLL.

Men weet thans van de godsdienstvormen, die vóór den Islām op Java geheerscht hebben, genoeg om te kunneu vaststellen, dat het Wișnuïsme naast het Çiwaïsme en het Noordelijke Buddhisme of Mahāyānisme daar slechts een zeer bescheiden rol gespeeld heeft.

Dit blijkt o. a. uit het betrekkelijk geringe aantal Wiṣnu-beelden, die het Bataviasche en Leidsche Museum bezitten, als men dit vergelijkt met de groote menigte Buddha-, Bodhisatwa- en Çiwa-beelden, om vau de Durgā- en Gaṇeça-voorstellingen niet eens te spreken. De vele Wiṣnu-beelden, die Leemans in zijne Beschrijving der Indische oudheden van het Rijks-Museum van Oudheden vermeldt, zijn bij nader onderzoek gebleken, voor het meerendeel Çiwa- of Buddha- resp. Bodhisatwa-beeiden te zijn.

In de Oudjavaausche letterkunde treft men nog veel minder sporen van Wiṣṇu-dienst dan van Mahāyānisme aan. Zelfs het Mahābhārata, dat oorspronkelijk sterk Wișnuïtisch getint was en waarin Kṛșnaa, een van Wiṣṇu's awatāra's naast de $\mathrm{P} \bar{a}$ ṇ d̦a a's een hoofdrol vervult, is in het Oudjavaansch geheel Ciwaïtisch bewerkt. In het begin van het $\overline{\mathrm{A}}$ çramawāsaparwa b.v. wordt Çiwa in een zeer corrupte āryāstrophe angeroepen en in het begin van het $\overline{\mathrm{A}} \mathrm{di}$ a rwa treedt Cִiwa als schepper op, terwijl in den Sanskṛt-tekst Puruṣa-Brahmā als zoodanig genoemd wordt.

Toch vindt men in de onuitgegeven Oudjavaansche literatuur eenige tooverspreuken, die wijzen op vereering van Wiṣnu u o. a. in zijn awatāra als Narasingha en van zijn wāhana Garuḍa. Daar deze mantra's alleen in handschrift bestaan, schijnt het mij van belang toe, deze meer algemeen bekend te maken, ook in verband met de Narasingha- en Garuḍa-beelden. Beginnen wij met de mantra's ter eere van $\mathrm{Narasingha.} \mathrm{Een}$ 
hiervan ontleenen wij aan cod. 5320 leg. Warn. (uit de Lombokcollectie), een ĕmbat-ĕmbatan van 7 folia. Dit palmbladhandschrift begint met Ciwaïtische spreuken, die men moet uitspreken bij de reinigingen met water (a ĕkĕmuh en adyus, d. i. het spoelen van den mond en het baden), om de zonden te doen verdwijnen, zooals de Oudjavaansche schrijver zich uitdrukt: sâsing doṣa hilang donya (het verdwijnen van alle zonden is het doel ervan). Daarna volgt (op regel 4 van fol. 1 b) een mantra, die Narasinghadhyāna heet en waarin elk van zijne attributen afzonderlijk aangeroepen wordt, zoodat aan het slot staat: Katuduhan ira sang hyang astra iki (dit is de aanwijzing der goddelijke wapens). Met het oog op de belangrijkheid voor de iconographie geven wij hier dezen mantra in zijn geheel in transcriptie weer :

Om Narasinghāya sarwaçatruwināçāya paṭ. Narasingha d hy āna sahāstra nira.

Uṃ hrum khaḍ geçwarāy a sarwaçatruwināçāya paț; pūr, ma, uṃ hrụ̣ çangkhapāñcajan yāya sarwaçatruwināçāya, paț, gneng muka, ma, ụ̣ hrum cakrasudarçanāya sarwaçatruwināçāya paț, da, muka, ma, ụ̣ hruṃ ga dāy a sarwaçatruwināçāya paț, neng muka, ụ̣ hruṃ cāpāya sarwaçatruwināçāya paṭ, pa, muka ma, um hruṃ, ça rāya sarwaçatruwināçāya paț, ba, muka, ma, ụ̣ hrụ̣ țangkāya sarwaçatruwināçāya paț, u, muka ma, ụ̣ hruṃ ardhacandrāya sarwaçatruwināçāya paṭ, u, muka, ma, sma, katuduhan ira sang hyang astra iki.

Hieruit ziet men, dat achtereenvolgens aan $\mathrm{N}$ arasing ha en al zijne attributen hulde bewezen wordt. Achter ieder volgt het epitheton: sarwaçatruwināçāya (aan den verdelger van alle vijanden). Als zijne attributen worden genoemd: het zwaard (khadga), de schelphoorn (çangkha) Pāñcajanya, de discus Sudarçana, de knots ( $\left.\operatorname{gad} \bar{a}{ }^{1}\right)$, de boog (cāpa), de pijl (çara), de beitel (țangka) en de halve maan (ardhacandra). De tusschengevoegde woorden zijn gedeeltelijk uitroepen, heilige syllaben ( $\mathrm{um} \mathrm{hrum}$ ), gedeeltelijk aanwijzingen van de richting, waarheen men zich moet wenden bij het opzeggen van den mantra.

De volgende wordt verdeeld in den tīkṣṇa mantra, waarbij men zich $\mathrm{Narasingha}$ in zijue vreeswekkende gedaante voorstelt en den somyamantra (Skr. saumyamantra), waarbij hij in

1 De naam van deze (Ka umodakī), die men hier zou verwachten, komt in den mantra niet voor. 
zijne weldadige hoedanigheid gedacht werd. Deze mantra's luiden als volgt :

Om Narasinghāya namah.

Ugra wi ș̣̣u mahāwīryạ̣ jwalantạ̣ sarwatomukham.

Nṛsinghābhīṣaṇa ṃ mṛtyumṛtyun namāmy aham.

Tìṣnamantra iti.

Oṃ hrụ̣ çrīmān N ṛsinghaçaraṇa ṃ çaraṇo pramadhye çrīmate Nringhāya namah. Somyamantra.

Iti bajra Narasingha kahilangan ing çatru don ira mwang çarīrarakṣaka.

De vertaling der laatste Oudjav. woorden luidt: "Dit is de wajra van Narasingha, die de verdelging der vijanden en eigen bescherming (of bescherming van het lichaam) ten doel heeft".

Ten slotte nog: Oṃ Narasinghāya namah.

Taptahāṭakakeçägra jwalatprābhakalocanaḥ,

bajrādhikanakhasparça dībyasingha namo'stu te.

Iti Narasinghāyudha, ripusanghāra don ira, uccāraṇākna ri tatkāla ning yuddhakrama, haywa luptan.

Het Oudjavaansche slot beteekent: "Dit is de Narasinghāy u dha, welks doel het is de vijanden te verdelgen. Men moet dit uitspreken tijdens den strijd en men moet het niet verzuimen".

De nam van den geheelen mantra is dus Narasinghāyudha.

Een anderen Wiṣnuïtischen mantra vindt men in cod. 5325 (leg. Warn.). Deze heet Wiṣnuuṣṭawa (lof van Wiṣṇu) en begint als volgt :

Oṃ oṃ namo Wiṣṇu trimukhanam, trinayana, caturbhujam, kṛṣnawarṇa sphațikāṇḍaḥ, sarwabhūṣaṇanīlanạ̣, cakrahasta mahātīkṣna, ātmarakṣa hamprusthānaḥ, amṛtāñjīwano dewa, sarwaçatruwinaçanaṃ. Paṭ, swâhâ !

De Oudjavaansche vertaling (?) luidt: Hiḍẹp bhațāra Wiṣnu ri tiktanta, matrinayana, caturbhuja, pinakāstra cakra, sahabhūṣaṇa.

Zooals men ziet geeft dit slechts een gedeelte van de verknoeide Sanskrrtwoorden weer, want de O. J. woorden beteekenen : "Weet, dat god Wișnu in uw lever is, hij heeft drie oogen en vier armen, de cakra strekt hem tot wapen, hij is versierd".

Eigenaardig is in dezen mantra, dat Wișnau hier met drie hoofden voorgesteld wordt, dus als Trim $\bar{r}$ ti. Met vier armen wordt hij gewoonlijk ook in de steenen en bronzen Oudjavaansche beelden afgebeeld en de cakra is in die beelden een zijner vier gewone attributen. De samenstelling hamprusthānah is hybri- 
disch, daar zij uit het O.-Jav. ha mpĕr $\bar{u}$ (vgl. Mal. hampĕdu enz.) = "gal, lever" en het Skr. woord sthāna (plaats) bestaat. Daarentegen zou de O.-Jav. vertaling ri tiktanta ${ }^{1}$ (letterlijk: in uwe bitterheid) zonder het woord ham prusthāna h onduidelijk zijn.

De voorstelling, dat goden in de verschillende lichaamsdeelen zetelen, komt bijna in al deze tooverspreuken voor. Na de invoering van den Islām zijn de Indische godennamen eenvoudig vervangen door die der Moslimsche profeten, van Adam tot Mohammad.

Het slot van dezen mantra is van minder belang, daar Wiṣṇu er niet meer in genoemd wordt. Het begint met: "Ah siti pralina moktaḥ, siddha lĕpas, mijil saking tan hana" enz.

Het begin van cod. 5332 (leg. Warn.) wordt gevormd door een mantra, die ook Wiṣnuṣțawa heet, evenals cod. 5325, doch daarvan afwijkt. Deze luidt aldus :

Oṃ namo'stu Puruṣottamāya, paramaripu, parapuraharaṇa, parākramāya ......

Mahābalāya ca, jāgraswapna, supta, turya caturbhujāya, Nārāyaṇa, Narasingha wāmanāya, Narajanārdhanāya, Janagadāyudhi Dānawāntaka, Ripumadana Pāñ ca jan y a, Su darça na āyudhāy a, daityadānawa, yakṣa, rākṣasa, piçācabhūtagaṇa.... gandharwa madhuragìta, surawidyādhara, ṛșiprabhṛti....

Purușo'nautasamudrāçrayī, khaga warawarendraçrī priyo, dhanapriyo, Waiçrawaṇānggako'sman, rakṣa tasman, gopayantu swāhā!

Hierbij zijn de al te corrupte plaatsen weggelaten. Men ziet, hoe $\mathrm{W}$ iṣṇu hierin aangeroepen wordt, o. a. als vierarmig, ook in zijn Narasingha- ei wāmañ̄watāra, waarbij drie van zijne bekende attributen genoemd worden : de knots ( $\operatorname{g}$ a d a $)$, de çang kha $\mathrm{P} \bar{a}$ ñcajanya en de $\mathrm{cakraS} \mathrm{S}$ darçana. Hij wordt de opperheer van allerlei booze en goede geesten genoemd (daitya, dānawa, y akṣa, rākṣasa, piçāca, gandharwa, widyādhara enz.). Ook Garuḍa, de voortreffelijkste der vogels (khagawara), wordt niet vergeten en $\mathrm{W}$ iṣṇu wordt als belichaming van Waiçra wạ̣a (Kuwera) beschouwd. De bescherming van al deze wezens wordt in dezen mantra aangeroepen.

Uit de Oudjavaansche woorden aan het slot blijkt het doel, waarmede deze tooverspreuk uitgesproken wordt : "Ātmarakṣa don ira, apan sira mahāwiçeșa" of : "Eigen bescherming is het doel ervan, want hij is zeer uitstekeud".

1 Tikta is een synoniem van pahit. Vandaar de naam Wilwatikta voor Majapahit. 
Op dezen Wiṣnuütischen W iṣṇuṣṭa wa volgt in hetzelfde haudschrift een zuiver Çiwaïtische mantra, die Trilokyawijaya heet, doch dien wij hier niet verder bespreken.

Een vierde Wiṣnuïtische mantra is de Wiṣṇupañjaram, die voorkomt in cod. 5319 en 5331 leg. Warn. Deze begint met:

Oṃ çrī Wiṣṇupa ñjaram diwyạ̣, abhedyạ̣ duṣțāwaraṇam, ugratejo mahāwīryạ̣, sarwaçatruwināçanam.

Tripuran dahyamānantu, brāhmaṇam īçwarangkṛtạ̣.

In dezen mantra worden de verschillende namen en incarnaties van $\mathrm{W}$ iṣṇu als beschermers van de lichaamsdeelen voorgesteld, b.v. :

Pādo rakṣantu Gowīndo, janggābhyān̆ ca Triwikramaḥ, Ūrwantang Keçawo rakṣet, prșțhe rakṣantu Wāmanaḥ.....

Bāhu dwo Wāsudewa ç ca, Narasingha hṛdisthitaḥ, kaṇthe rakṣantu $\mathrm{W}$ arāhaḥ, K ṛṣna ç ca mukhamaṇḍalạ̣......

Netre Nārāyaṇo rakṣet, lalāṭe Garuḍadhwajạ̣, kapāle W a in a te y a ç ca, K e çaw o çirahsaṃstitạ ......

Ook als in de windstreken te zetelen worden zij voorgesteld, b.v.:

Pūrweçyām Pụ̣ ḍarīkākṣa, āgneye Çrīdharas tathā,

Puruṣottamo wāruṇyām, wāyawyām Pītawāsasaḥ.

Gadādharaç ca kowīryām, aiçānyāṃ Çaugkham adhișthet. Pātālang K ūrma rakṣantu, ākāçaç ca Suda rçạ̣a hạ.....

Wiṣnupañjarạ̣ Wiṣno'ham, wicarāmi mahītale, rājadwāre pate gore, sanggrāme ripusangkate.....

Ḍākiṇībhūtapreteșu bhayo nāsti kadācana, aputre labhate putrạ̣, dhanahīno dhanaṃ labhet, mucyate sarwarogeṣu, Wiṣnulokaṃ sa gacchati.

Uit de laatste woorden blijkt het doel van den mantrã : hij beschermt tegen allerlei booze geesten (ḍākiṇ̂̄'s, bh ūta's en preta's) en tegen de vijanden in den strijd, geeft kinderen aan kinderloozen en geld aan armen, verlost van alle ziekten en wie dezen mantra reciteert, gaat naar Wiṣnu u's hemel.

Aan het slot staat: "Iti sang hyang Wiṣṇupañjaram, mahābhāra, haywa palĕpalěh"; d.i.: "Zoo luidt de Wiṣṇupa ñja ram. Deze is zeer belangrijk en men moet hem niet geringschatten".

Behalve deze vier mantra's, bestaat er nog een vijfde, die bepaaldelijk an Wiṣṇu in zijn awatāra als Narasingha gewijd is. Deze heet in cod. 5317 leg. Warn. prayoga sang hyang $\mathrm{N}$ arasingha en daarin wordt o. a. zijne overwinning op Hirangakaçipu bezongen. Dezelfde mantra komt voor in cod. 
5318 en 5319 leg. Warn., doch heet daar (in cod. 5319) Așțaka Narasingha. Daar echter deze tooverspreuken uitsluitend uit verknoeide Sanskrtverzen bestaan, zullen wij die verder niet bespreken, te meer omdat de bovengenoemde reeds voldoende aangeven, hoe dergelijke spreuken er uitzien.

Van meer belang is de Garuḍ e y mantra, waarvan verscheidene hss. bestaan, o. a. cod. 3890 leg. Warn. (uit het legaat Van der Tuuk) en cod. 5155, 5251, 5306 en 5322 leg. Warn. (uit de Lombok-collectie). Het begin hiervan gelijkt veel op de dhāraṇīs, die Foucher in het tweede deel zijner Étude sur l'iconographie bouddhique (1905) uitgegeven heeft, voor zoover ook hier nauwkeurig wordt aangeduid, hoe de god, dien men wil aanroepen, er uitziet. Voor de iconographie kunnen dergelijke mededeelingen groote waarde hebben. Uit de Sanskṛtverzen, die op den Oudjavaanschen tekst volgen, blijkt dat het begin van dezen tekst verloren is gegaan.

De Garudeyamantra ${ }^{1}$ luidt als volgt :

Nihan tingkah sang hyang Garuḍe y a. Hiḍĕp çarīra nira kuning warṇa ning suku nira, makahingan ing tūr, putih warṇa ning pupu nira, makahingau ing nābhi, mirah warṇa ning ḍạ̣a nira, makahingan ing gulū, hirěng warṇa ning muka, makahingau ing çirah mwang patuk, trinayana, caturbhuja sira, bajrâstra. Mangka ta hiḍĕpa nira.

De vertaling dezer Oudjavaansche woorden is: "Als volgt is de Sang hyang Garudeya. Weet (of: stel u voor) zijn lichaam, geel is de kleur zijner voeten, tot de knieën, wit de kleur zijner dijen tot zijn navel, rood de kleur van zijn borst tot zijn keel, zwart de kleur van zijn gelaat tot zijn hoofd en zijn snavel. Hij heeft drie oogen, vier armen en den wajra als wapen. Zoo moet men hem zich voorstellen".

Daarop volgen deze Sanskṛtverzeu :

Mahābhairawarūpañ ca suḍāngșțra raktalocanah, mahānāso mahāgrīwo bāyuwegasamāçritaḥ (1).

Jñānaḥ kāñcanawarṇac ça ${ }^{2}$ nābhiç caiwācalākṛtiḥ, kaṇthaç caiwārkasannibhạ̣ $\overline{\text { ūdhwābhinnañ }}{ }^{3}$ janäkṛtiḥ (2).

1 De geschiedenis van Garuḍa was op Java bekend. Zij komt voor in het Oudjav. $\bar{A}$ diparwa (p. 36-45 müner editie).

2 Misschien te lezen: Jñeyaḥ añjanawarṇaçea (?) Conjectuur van Prof. Speyer.

${ }^{3}$ Lees: mūrdhābhinnañ (?), volgens Prof. Speyer. 7• Volgr. VI. 
Mahāpitạ̣ bhawed warṇaṃ jānwantạ̣ pādamūlakam, mahäçwetạ̣ bhawed warṇaṃ nābhyantam ūrumūlakạ̣ (3). Mahāraktạ̣ bhawed warṇaṃ hṛdmūlāntalukantakạ̣, mahākṛ̣̣̣iam bhawed warṇaṃ wadanādiçirāntakạ̣ (4).

Zooals men ziet, zijn vers 1 en 2 niet in het Oudjavaansch vertaald, terwijl daarentegen de laatste regels van den Oudjav. tekst (van trinayana caturbhuja af) in het Sanskṛt ontbreken.

Ten slotte volgen nog deze Oudjavaansche woorden:

Tlas pwa kahiḍĕpan ira, dĕlö kang pinangan kinasangçayan. O ṃ ākṣipāya naınaḥ, ma, wiṣāpaha. Tělas kahiḍĕpa tāmṛta iking pinangan tĕmahauya. Nihan mantra: Oṃ, ạ̣. Khagarājāya n a mas swāhā. Tĕlas pwa, andělakĕn ing padma hṛdaya, wijākșara nira. Nihan kasimpĕnan ira saing hyang Garuḍ e ya. Oṃ, hkṣaṃ, ọ̣, uiçwasa kuța nira. Japa nira muwah, lwĕh kunang mautra muwah: Oṃ kukuni kukuni wiṣahari, wiṣahariharan, yā ṃ, lāṃ, māṃ, bhā ṃ, wiṣadaham swāhā. Mantra pangilang sarwa lwěh wiṣa huwus kapangan. Ọ̣, yāṃ, bāyutatwa, hirĕng. Oṃ lạṃ, tejatatwa kuning. Oṃ hkṣaṃ namaḥ oṃ h i ṃ, n a ma ḥ. Dĕlö wiṣa, ma, oṃ, iskara çabda bhațārî̀ manghanâkĕn, iskara bhațāra manghĕlakĕn. Iti sang hyang Garuḍeya samāptam. Rahasya sira, kayatnākua de sang sādhaka.

Uit dit slot blijkt, dat men dezen mantra moest opzeggen vóór het eten, ten einde beveiligd te zijn tegen vergiftiging. Waarschijnlijk gold Garuḍa als vijand der slangen tevens als beschermer tegen hun vergif. Vandaar de woorden wiṣāpaha, wiṣahari, wiṣadaha enz. in de tooverspreuk.

De laatste woorden beteekenen: "Hiermede is de Sang hyang Garude ya voltooid. Het is een geheime spreuk, die de geloovige met zorg moet bewaren".

$\mathrm{Na}$ de behandeling der teksten gaan wij over tot de Oudjavaansche beelden, ten einde te zien, in hoe verre deze aan de in de teksten genoemde vereischten voldoen, wat de attributen van $\mathrm{W} i s ̣ n$ u en de kleuren enz. van Garuḍa aangaat. Voor het laatste kunnen wij alleen de moderne Balineesche beelden vergelijken.

Wat de attributen in de vier handen der steenen $W$ iṣṇubeelden betreft, deze bestaan uit deu cakra Sudarçana, den çangkha Päñcajanya, den lotus en de gadā. De laatste komt zelden bij de steenen beelden voor (bij die van 's Rijks Ethnogr. Museum slechts eenmal), doch wel bij de bronzen beelden. Alleen het 
steenen beeld, dat Leemans in zijne Beschrijving der Ind. oudheden van het Rijks-Museum van Oudheden ( $\mathrm{n}^{0}$ 6) W iṣṇu noemt, ${ }^{1}$ heeft in de achterste rechterhand het boveneinde van een afgebroken knots. Naast den god staan twee vrouwen, die Leemans Laksmi en Satiavana noemt. De laatste naam is eene verbastering van Satyabhāmā (in het inventarisstuk staat: Satiavama). Als dit juist is, moet de andere vrouw Rukmiṇi en het hoofdbeeld K ṛṣna voorstellen.

Bij de bronzen Wiṣnu-beelden wordt deze god gewoonlijk met Garuḍa voor op het voetstuk voorgesteld. Garuḍ a heeft daarbij de gedaante van een gevleugelden man met vogelsnavel.

Behalve deze gewone Wișṇu-beelden (ten getale van vijf, waarvan drie met Garuḍa) bezit 's Rijks Ethnogr. Museum sedert November 1907 ook nog drie awatāra's van Wiṣṇu, die daar tot nu toe ontbraken, n.l. den Matsyāwatāra, waarbij Wiṣṇu met menschenlichaam, dat in een-vischstaart uitloopt, voorgesteld wordt, evenals op plaat 5, fig. 2 van Coleman's Mythology of the Hindus; den Warāhāwatāra, waarbij hij als een man met een everzwijnkop, met den çangkha, lotus, gadā en cakra als attributen, op Hiraṇyākṣa's buik staat, evenals plaat 7, fig. 1 van Coleman's boven aangehaald werk en als het steenen beeld $\mathrm{n}^{\circ} 21 a$ in Batavia (Not. Bat. Gen. XXX, bijlage XIX). Ten slotte de Narasinghāwatāra, die met het oog op den boven medegedeelden mantra voor ons het meeste belang heeft.

Dit laatste beeld (Serie 1630/31) is eene voorstelling van een zittenden vierarmigen man met leeuwenkop, die bezig is met zijne nagels de borst en buik van Hiraṇyakaçipu, die op zijn schoot ligt, te verscheuren. Ook het Bataviaasch Genootschap bezit van

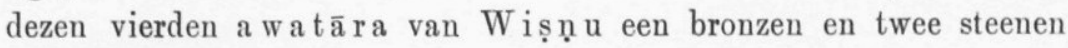
beelden, resp. $n^{\circ} 491 a, 21$ en $21 a$ (Not. Bat. Gen. XXVIII, pag. LXVIII en XXXI, bijlage XVIII). In deze Javaausche beelden nu, zoowel als in eene Indisch, afgebeeld bij Coleman, l. c. plaat 8, figuur 1, wordt Narasingha geheel ongewapend voorgesteld. Op eene andere plaats echter, n.l. in de Milloués Petit guide illustré au musée Guimet (Paris, 1894, pag. 17) wordt $\mathrm{Narasingha}$ zesarmig afgebeeld, o. a. met den çangkha als attribuut. Aan eene dergelijke voorstelling, doch met meer attributen, moet de mantra Narasinghāyudha beantwoorden. Er bestaat

1 Thans is dit beeld geïnventariseerd als Serie 1403/1859. 
hier dus tusschen de teksten en de beelden zeer weinig overeenstemming.

Evenzoo is het gesteld met de Garud a-voorstellingen, vergeleken met den mantra Garuḍeya. Van het voorkomen der oude Javaansche Garuḍa-beelden kan men door de raadpleging der platen 8-11 achter de verhandeling van dr. Brandes over "De verzameling gouden godenbeelden, gevonden in het gehucht Gĕmoeroeh bij Wanasaba" (Tijdschr. v. Ind. T. L. en Vlk. XLVII, pag. $552-577$ ) zich een duidelijk denkbeeld vormen. Daaruit blijkt, dat hij nergens met drie oogen of met vier armen voorgesteld wordt, zooals in den Garudeya mantra.

Wat de kleuren betreft, hierbij moet men zich bepalen tot de vergelijking der Balische houten beelden, die Wiṣṇu op Garuḍa voorstellen. Bij de nieuwere beelden, die 's Rijks Ethn. Museum hiervan bezit, o. a. die welke in September 1907 ten toon gesteld waren, ${ }^{1}$ beantwoordt geen enkele kleur aan die, welke de mantra voorschrijft, doch bij een oud beeld, uit het Kabinet van zeldzaamheden (Serie 360/7224) wordt Garuḍa werkelijk met een zwart gelaat voorgesteld, zooals de mantra zegt: hirĕng warṇa ning muka. Misschien is dit nog een overblijfsel van de oude traditie.

De conclusie, waartoe wij komen, is deze: de Javaansche Wiṣṇuïeten plachten vóór het eten den mantra Garuḍeya te reciteeren, in de meening, dat de aanroeping van deu vijand der slangen voor hen een talisman zou zijn tegen vergif, zoo dit met de spijzen vermengd was. Voordat zij ten strijde trokken, reciteerden zij den mantra Narasinghāyudha, in de hoop, dat de wapens, die daarin genoémd werden, hunne vijanden zouden verslaan. Tusschen de wijze van voorstelling van Narasingha en Garuḍa in die mantra's en in de steenen, brouzen en houten beelden, voor zoover wij die kennen, bestaat echter geen overeenkomst.

1 Dr. H. H. Juynboll, Gids Tentoonst. v. voorwerpen uit Bali, pag. 28, $\mathrm{n}^{\circ} 186$ en 187. Zie ook de daar aangehaalde werken van Pleyte (Indonesian Art), Meyer (Alterthümer) en de Milloué (Cat. Mus. Guimet). 